\title{
Optimal foraging and fitness in Columbian ground squirrels
}

\author{
Mark E. Ritchie* \\ School of Natural Resources, University of Michigan, Ann Arbor, MI 48109-1115, USA
}

Summary. Optimal diets were determined for each of 109 individual Columbian ground squirrels (Spermophilus columbianus) at two sites in northwestern Montana. Body mass, daily activity time, and vegetation consumption rates for individuals were measured in the field, along with the average water content of vegetation at each ground squirrel colony. I also measured stomach and caecal capacity and turnover rate of plant food through the digestive tract for individuals in the laboratory to construct regressions of digestive capacity as a function of individual body mass. Finally, I obtained literature estimates of average daily energy requirements as a function of body mass and digestible energy content of vegetation. These data were used to construct a linear programming diet model for each individual. The model for each individual was used to predict the proportion of two food types (monocots and dicots) that maximized daily energy intake, given time and digestive constraints on foraging. Individuals were classified as "optimal" or "deviating", depending on whether their observed diet was significantly different from their predicted optimal diet. I determined the consequences of selecting an optimal diet for energy intake and fitness. As expected, daily energy intake calculated for deviators (based on their observed diet proportion) was less than that for optimal foragers. Deviating foragers do not appear to compensate for their lower calculated energy intake through other factors such as body size or physiological efficiency of processing food. Growth rate, yearly survivorship, and litter size increase with calculated energy intake, and optimal foragers have six times the reproductive success of deviators by age three. Optimal foraging behavior, therefore, appears to confer a considerable fitness advantage.

Key words: Optimal foraging - Fitness - Ground squirrels - Energy intake - Growth rate

The development of optimal foraging theory (see Pyke 1984, Stephens and Krebs 1986) has been based on the assumption that foragers should choose the diet that maximizes their fitness, or lifetime reproductive success (Christiansen et al. 1977; Endler 1986). Optimal foraging theory explicitly assumes that there is some "currency" (e.g. energy, nutrients, or time) for fitness (Schoener 1971; Pyke 1984; Stephens and Krebs 1986). Maximizing acquisition of a particular "currency" can be viewed as a "goal" of the forager.

Energy maximization and feeding time minimization are two goals which have been proposed for foragers (Schoener

\footnotetext{
* Current address: Department of Ecology, Evolution and Behav-
} ior, University of Minnesota, Minneapolis, MN 55455, USA
1971; Belovsky 1978; Hixon 1982). For energy maximizers, energy is the appropriate currency. In this case, foragers attempt to maximize their daily energy intake within their available feeding time. This goal is expected when fitness depends on the amount of energy that can be invested in survival or production of offspring. For time minimizers, time is the appropriate currency. In this case, foragers attempt to spend only enough time feeding to satisfy minimum energy or nutritional requirements so as to maximize the time available for other activities. This strategy is expected when fitness depends on the amount of time spent caring for young, searching for mates, avoiding predators, etc.

Survival and reproduction is associated with increased energy intake in a variety of taxa (e.g. Leslie et al. 1955; Lack 1966; Ayala 1967; Verme 1969; Morton and Sherman 1978; Porter et al. 1983; Dobson and Kjelgaard 1985a, b). In addition, many studies have also tested whether animals maximize their instantaneous rate of energy intake (e.g. Werner and Hall 1974; Krebs et al. 1974, 1977; Goss-Custard 1977; Elner and Hughes 1978). In these studies, the authors assume that energy is the currency for fitness, but cannot test this assumption by analyzing foragers' diets because both time minimizers and energy maximizers may attempt to maximize their instantaneous rate of energy intake (Schoener 1971; Belovsky 1984a). Nevertheless, there is evidence that some animals, particularly herbivores, maximize their daily energy intake [i.e. are true energy maximizers (Belovsky 1978, 1984a, b, 1986a, b; Belovsky and Ritchie 1990)]. None of these studies, however, demonstrate greater fitness for individuals that forage optimally. A major assumption of optimal foraging theory, therefore, remains untested.

In a previous paper (Ritchie 1988), I show that individual Columbian ground squirrels (Spermophilus columbianus) vary in their ability to consume diets that maximize their daily energy intake. The "optimal foraging ability" of an individual is measured as the absolute value of the difference between its optimal and observed diets. An individual's foraging ability is consistent over time within a season and is not affected by food abundance, thermal regime, or social environment. Consequently, foraging ability can be viewed as an individual behavioral character. I classified individuals into two groups: "optimal" and "deviator", based on whether an individual's observed diet was significantly different from its energy maximized diet. As a result, these individuals provide an opportunity to compare fitness components among individuals with different foraging abilities and therefore measure the consequences of deviating from an optimal diet. 
To demonstrate that optimal foragers have greater fitness, each of the following hypotheses must be tested.

Hypothesis 1. Deviators do not compensate for the energy intake lost due to incorrect diet choice through other factors, e.g. body size, cropping rates, activity time, or the physiological efficiency of processing food.

Testing this hypothesis shows that optimal and deviating foragers are alike in most characters other than foraging ability. If so, any difference in calculated energy intake among optimal and deviating foragers results only from their difference in optimal foraging ability.

Hypothesis 2. Individuals with greater energy intake will have greater growth, survival, and reproduction.

Testing this hypothesis shows that energy is an appropriate currency for fitness.

Hypothesis 3. Optimal foragers will have greater growth, survival, and reproduction than deviators.

Testing this third hypothesis ensures that the increment in fitness gained from greater energy intake is not overwhelmed by the increment in fitness gained or lost from other characters. For example, deviators might be subject to lower predation risk. The fitness gained by being an optimal forager might be exceeded by the fitness lost from predation risk.

\section{Methods}

The study was conducted during May-July, 1983-1986, using two populations of ground squirrels (JB and RJ-2, Belovsky and Ritchie 1990) on pasturelands near the National Bison Range, Montana. Detailed descriptions of the study site and vegetation characteristics are provided in Belovsky and Ritchie (1990). During the course of the study, 109 individuals ( 40 adults, 15 yearlings, and 54 juveniles) were trapped, marked, weighed, aged, and checked for reproductive condition. Each year, adults were trapped 3-10 days before juveniles were weaned and again, along with juveniles, 1-14 days after weaning.

In order to test Hypotheses 1-3 above, I calculated the energy budgets and measured the major fitness components of individuals whose optimal foraging ability was also measured (Ritchie 1988). Observations of individuals' foraging behavior were made within 7 days of their last capture. Consequently, energy intake and foraging behavior were measured for all individuals at approximately the same point in the annual active period each year: 7-14 days after weaning in early June. In 1986, a subsample of 6 adult females were measured for foraging ability and energy intake 7 days prior to weaning to test whether individuals always attempted to maximize their daily energy intake or merely responded to immediate physiological demands (Millar 1975). I examined potential relationships between optimal foraging ability, daily energy intake, and three components of fitness: daily growth, overwinter survivorship, and yearly reproduction by adult females.

\section{Deviation from an optimal diet}

Columbian ground squirrels eat primarily vegetation: herbaceous monocots (primarily grasses) and dicots (primarily forbs). In a previous study, I found that, in general, individual ground squirrels approached energy maximized diets rather than time minimized or random diets (monocots and dicots in their proportion in the environment) (Ritchie 1988). I consequently used the energy maximized diet for each individual as their optimal diet. In each case, the optimal diet provides a reference against which the individual's observed foraging performance can be compared.

To determine the energy maximized diet for each individual squirrel, I used a linear programming optimization model (Westoby 1974; Belovsky 1978, 1984a; Karasov 1985). This model is appropriate because at my study site, monocots and dicots are distributed patchily relative to each other so that they cannot be searched for at the same time (Belovsky 1986a).

A linear programming model considers the impact of different constraints on a forager's diet choice. The food intake of ground squirrels is constrained potentially by their (1) daily digestive capacity and its utilization by the bulk (wet wt/dry wt) of plant foods, and (2) maximum daily feeding time and its utilization by the time to crop plant foods (Belovsky 1986a; Belovsky and Ritchie 1990). The impact of these feeding constraints on food intake can be described with linear equations representing each constraint (Table 1) (Belovsky 1978, 1984a, 1986a). The equations describe the combination monocots and dicots that exactly satisfy the constraints (Fig. 1).

I estimated the parameters of the constraint equations for each individual (e.g. Table 2) [for details, see Ritchie (1988)]. Activity times (an upper limit to feeding time) and cropping times measured for each individual were used to calculate the feeding time constraint for each individual. Maximum daily activity time appears to be set by the thermal environment because only certain periods of the day have thermal conditions that allow ground squirrels to be above ground without overheating or becoming hypothermic. The activity time observed for ground squirrels is not significantly different from that predicted by thermal conditions (Belovsky and Ritchie 1990). Consequently, the observed activity time for an individual should correspond to an upper limit for feeding time.

Table 1. Equations to construct the linear programming models for each individual in the study

\section{Food Eaten}

$m=$ amount of monocot (dry mass) consumed per day

$d=$ amount of dicot (dry mass) consumed per day

Time Constraint:

$T \geq c_{m} m+c_{d} d$

Digestive Constraint:

$D=$ (turnover rate) $\times($ stomach + caccum capacity $)$

$=\left(3.95 \mathrm{e}^{45.6 / W}\right)(0.19 W)$

$=0.75 W \mathrm{e}^{45.6 / W}$

$D \geq b_{m} m+b_{d} d$

Hibernation Energy Requirement Constraint:

Adults:

$\mathrm{H}=5.72 \times \mathrm{BMR}=5.72\left(1.63 W^{0.75}\right)$

$=9.32 W^{0.75}$

Juveniles:

$\mathrm{H}=8.12 \times \mathrm{BMR}=8.12\left(1.63 W^{0.75}\right)$

$=13.23 W^{0.75}$

$\mathrm{H} \leq \mathrm{e}_{m} m+\mathrm{e}_{d} d$ 
Table 2. Parameters in the linear programming models for two example juvenile females, one optimal forager (\#1) and one deviator (\#2). Variables from Table 1 are defined here

\begin{tabular}{|c|c|c|}
\hline \multirow[t]{2}{*}{ Parameter } & \multicolumn{2}{|l|}{ Individual } \\
\hline & $\# 1$ & $\# 2$ \\
\hline Body Size ( $W$ in $g$ ) & 165 & 130 \\
\hline $\begin{array}{l}\text { Activity Time }(\mathrm{T}) \\
\text { (min/day, } N=\text { days) }\end{array}$ & $270 \pm 26(3)$ & $315 \pm 16(3)$ \\
\hline \multicolumn{3}{|l|}{$\begin{array}{l}\text { Cropping Times } \\
\text { (min } / \mathrm{g} \text { dry, } N=\min \text { ) }\end{array}$} \\
\hline $\begin{array}{l}\text { Monocots }\left(c_{m}\right) \\
\text { Dicots }\left(c_{d}\right)\end{array}$ & $\begin{array}{l}5.06 \pm 0.97(18) \\
2.95 \pm 0.41(25)\end{array}$ & $\begin{array}{l}6.27 \pm 1.21(15) \\
5.22 \pm 0.78(14)\end{array}$ \\
\hline $\begin{array}{l}\text { Digestive Capacity }(D) \\
\text { (g wet mass/day) }\end{array}$ & $163.1 \pm 8.2$ & $138.5 \pm 7.3$ \\
\hline \multicolumn{3}{|l|}{$\begin{array}{l}\text { Food Bulk } \\
\text { (wet mass/dry mass) }\end{array}$} \\
\hline $\begin{array}{l}\text { Monocots }\left(b_{m}\right) \\
\text { Dicots }\left(b_{d}\right)\end{array}$ & $\begin{array}{l}1.64 \pm 0.35 \\
2.67 \pm 0.75\end{array}$ & $\begin{array}{l}1.64 \pm 0.35 \\
2.67 \pm 0.75\end{array}$ \\
\hline $\begin{array}{l}\text { Energy Requirements }(H) \\
(\mathrm{kJ} / \text { day })\end{array}$ & 609.1 & 509.3 \\
\hline \multicolumn{3}{|l|}{$\begin{array}{l}\text { Digestible Energy Content } \\
\text { (kJ/g dry) }\end{array}$} \\
\hline $\begin{array}{l}\text { Monocots }\left(e_{m}\right) \\
\text { Dicots }\left(e_{d}\right)\end{array}$ & $\begin{array}{r}9.44 \\
10.19\end{array}$ & $\begin{array}{r}9.44 \\
10.19\end{array}$ \\
\hline Predicted Diet (\% Monocot) & 38.4 & 25.1 \\
\hline Observed Diet (\% Monocot) & $35.6 \pm 4.5(5)$ & $30.4 \pm 3.6 *(5)$ \\
\hline
\end{tabular}

* Significantly different from predicted $(P<0.01)$

Activity times were measured by (1) scanning the colony every 15 minutes and recording the state of each individual: active (above ground away from the burrow entrance) vs. inactive (presumably in burrow), and (2) summing the number of 15 minute intervals an individual was observed active. Between scans, biting rates (bites $/ \mathrm{min}$ ) of monocots and dicots were measured during focal observations of each individual. Individual biting rates were multiplied by the average bite sizes (dry mass) of monocots and dicots for each age class (adults and yearlings combined vs. juveniles) (Ritchie 1988) to compute individual cropping rates $(\mathrm{g} / \mathrm{min}$ ).

Daily digestive capacity and food bulk measured for each individual were used to calculate the digestive capacity constraint for each individual. Daily digestive capacity is the product of digestive organ capacity $(S)$ (stomach plus caecum) and the number of times per day this organ empties (turnover rate, $R$ ). Both maximum digestive organ capacity and turnover rate were estimated for individuals as a function of live body mass ( $W$ in $\mathrm{g}$ ) from regression equations presented in previous studies [digestive organ capacity (Belovsky and Ritchie 1990): $S=0.19 W, r^{2}=0.99, N=48$; turnover rate (Ritchie 1988): $\left.R=3.02 \mathrm{e}^{45.6 / W}, r^{2}=0.56, N=11\right]$. The bulk (wet mass/dry mass) of monocots was measured at each site (Belovsky 1986a; Belovsky and Ritchie 1990; Ritchie 1988).

During the June foraging observations at my study sites, dicots are cropped more rapidly than monocots (Table 2). On the other hand, dicots are higher in water content than monocots and therefore fill a ground squirrel's stomach and caecum more rapidly (Table 2). Consequently, the energy maximized diet for all individuals reflects a trade-off between filling the digestive tract and utilizing maximum available feeding time.

The observed proportion of monocot and dicot in the diet of each of the 109 individuals was determined from the mean of five fecal pellets collected from each individual at its last capture prior to foraging observations (Ritchie 1988). Diet proportions were measured using microhistological techniques (Storr 1963; Sparks and Malechek 1968). These proportions were weighted by the relative dry-matter digestibilities of the two food types to account for their differential appearance in feces (Smith and Shandruk 1979). This is the most accurate method for analyzing diet composition from fecal samples. The observed diet proportion for each individual was used to calculate daily energy intake (see below) and to compare with the individual's predicted optimal diet.

An individual's observed mean diet proportion (among the five fecal pellets) was compared with its energy maximized diet predicted by the linear programming model using a $t$-test. The within-day variance in diet proportion among fecal pellets closely approximated between-day variance over the period of trapping and foraging observations for 10 individuals whose feces were collected on different days (Ritchie 1988). Since all individuals were captured at least once, I used within-day variation among pellets in the $t$-tests for all individuals. I used a Monte Carlo simulation technique to generate confidence intervals around the predicted diet for each individual, based on the variances in individual model parameter estimates (Ritchie 1988). I classified individuals as "optimal" if their observed diet was not significantly different from their energy maximized diet and as "deviators" if their observed diet was significantly different. I also measured an individual's deviation from an optimal diet as the absolute value of the difference between predicted and observed diets.

To determine if foraging ability changed with the local foraging environment and with time, I also compared individuals' deviations from their optimal diet in the field and then one month later in an enclosure with (1) extremely abundant, high quality food, (2) a relatively hot thermal environment, and (3) isolation from other individuals. An individual's deviation was correlated between field and enclosure $\left(r^{2}=0.62, P<0.001, N=22\right)$. This experiment suggested that an individual's classification did not appear to change within a season, though deviators tended to improve (35\% improvement in foraging ability) between years (Ritchie 1988). Furthermore, an individual's foraging ability was not modified by food abundance, thermal conditions, or social environment. This means that the relative energy intakes of individuals will be similar throughout a season, even though their absolute energy intakes may vary with seasonal changes in vegetation phenology and thermal environment (Kilgore and Armitage 1978, Karasov 1985).

\section{Energy budget}

To determine the potential cost of deviating from an optimal diet, I calculated the amount of energy available to an individual for growth and reproduction based on the following equation:

$$
Q_{S E}=Q_{D E}-Q_{M}-Q_{H}
$$


where $Q_{D E}=$ digestible energy intake

$Q_{M}=$ metabolism (daily energy expenditure)

$Q_{H}=$ fat storage requirements for hibernation

$Q_{S E}=$ surplus energy for growth and reproduction

This equation states that the energy intake remaining after excretion of undigested food and fecal nitrogen, and use of energy in metabolism and storing fat for hibernation, or surplus energy intake, can be used for growth and reproduction. I calculated surplus energy intake for each individual not to represent an actual measurement of energy intake, but rather to provide a clearer picture of how optimal and deviator foragers are able to meet their energetic requirements for survival and reproduction. Daily digestible energy intake can be calculated for individuals by using their observed diet and linear programming model. I estimated metabolic and hibernation costs on the basis of individual body size. Individuals of a given body size undoubtedly vary in these energetic costs, but measurement of individual energetic costs was not possible in this study. Consequently, these calculations only approximate surplus energy intake for individuals.

(a) Digestible energy intake $\left(Q_{D E}\right)$. I calculated digestible energy intake for each of the 109 individuals as the maximum amount of energy it could consume per day, on average, using an individual's linear programming model. The foraging constraints of each individual's model consist of combinations of monocots and dicots that represent different potential food (dry matter) intakes. However, an individual's observed diet proportion defines a point along these foraging constraint lines that corresponds to the maximum food intake possible within the individual's feeding time or digestive capacity (Fig. 1). Consequently, I calculated energy intake for each individual using the following algorithm. (1) Calculate the amount of monocots and dicots that that satisfy an individual's digestive and feeding time constraints, given its observed diet proportion. (2) Multiply the amount of monocots and dicots by their respective digestible energy contents and add the two values. Each constraint provides a different estimate of energy intake. (3) The digestible energy intake used for each individual is that computed with the constraint providing the lowest energy intake (Fig. 1). Note that this algorithm estimates daily energy intake based on the individual's observed diet, not its optimal diet. The energy intake calculated, will always be less than that obtained with the optimal diet.

$Q_{D E}$ can be estimated as

$Q_{D E}=\frac{T\left\{(1-p) e_{m}+p e_{d}\right\}}{\left\{(1-p) c_{m}+p c_{d}\right\}}$

or

$Q_{D E}=\frac{D\left\{(1-p) e_{m}+p e_{d}\right\}}{\left\{(1-p) b_{m}+p b_{d}\right\}}$

whichever is less; where $p$ is the observed proportion of dicot in the diet of the individual, and the other parameters correspond to those defined in Table 2.

The digestible energy content of monocots and dicots was obtained from other studies. The gross energy content of plant foods was $18.4 \mathrm{~kJ} / \mathrm{g}$ for monocots and $20.1 \mathrm{~kJ} / \mathrm{g}$ for dicots (Belovsky 1986a). Digestibility of each food type was based on the results of in vivo feeding trials (Belovsky and Ritchie 1990). Ground squirrels apparently select only food items highest in digestible energy, and monocot and

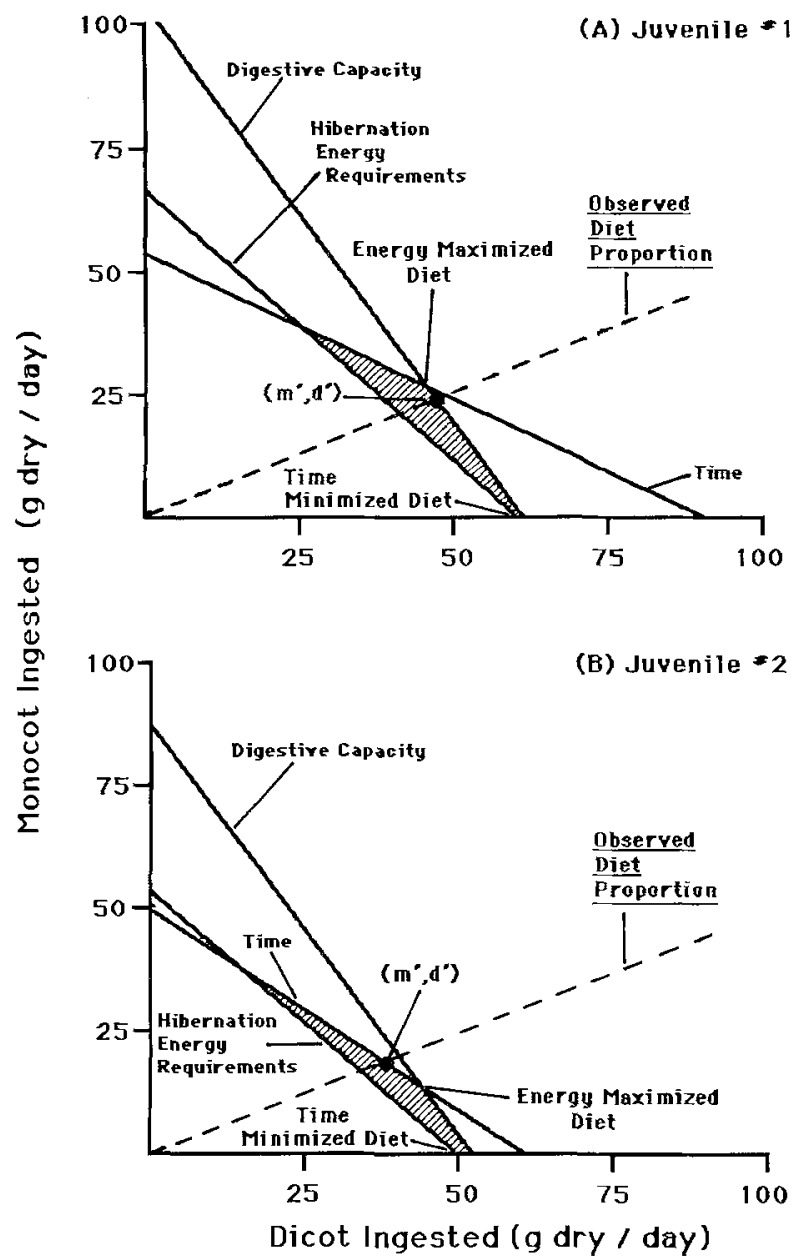

Fig. 1 A, B. Examples of the linear programming model for two juvenile ground squirrels. Constraints are labelled and the region of feasible diets is shaded. Equations and parameters for the constraint lines are shown in Table $1 \mathrm{a}, \mathrm{b}$. The two optimal solutions, energy maximization and time minimization, are indicated by arrow.

The model can be used to calculate the energy intake of an individual, given its observed diet. The point $\left(m^{\prime}, d^{\prime}\right)$ (closed circle) represents the intersection of the line of the observed diet proportion (dashed line) and the line of the limiting constraint (see text). In (A), the squirrel consumes a disproportionate share of dicot relative to the energy maximized diet, and is limited in its intake by digestive capacity. In (B), the squirrel consumes a disproportionate share of monocot and is limited in its intake by activity time. The energy provided by $m^{\prime}$ and $d^{\prime}$ estimates daily digestible energy intake. Surplus energy intake is the amount of energy remaining after hibernation and activity energy requirements are satisfied (see equations 1, 2)

dicot food items overlap considerably in their digestibility. Consequently, I used the average $51 \%$ in vivo digestibility found by Belovsky and Ritchie (1990) in feeding trials where individuals were fed an ad libitum mixture of both food types. This digestibility estimate does not account for potential individual variation in assimilation efficiency and the chemical properties of food selected by individuals.

(b) Urinary nitrogen. Nitrogen compounds remaining after catabolism of proteins are excreted as urine by ground squirrels and represent lost energy. Because the vegetation at my study site was relatively low in crude protein compared to animal foods (averaged 17.7\%, Belovsky 1986a), 
energy losses from the catabolism of protein are likely to be small. For example, Karasov (1982, 1985) and Kilgore and Armitage (1978) found urinary nitrogen losses to account for less than $2 \%$ of the average energy losses for ground squirrels. Such losses would explain only $0.5 \%$ of individual variation in energy intake in my study. Individual differences in diet (monocots vs. dicots), therefore, are not likely to lead to large variation in urinary nitrogen loss. As a result, I assumed that the contribution of urinary nitrogen losses to individual variation in surplus energy intake was negligible, and did not include urinary nitrogen losses in the energy budget model (Eq. 1).

(c) Metabolic costs $\left(Q_{M}\right)$. Ground squirrels are endotherms, although they may reduce their basal metabolic rate and body temperature while in the burrow (Wang 1979; Karasov 1981; Kilgore and Armitage 1978). Consequently, I used Kleiber's (1961) equation, $\mathrm{BMR}=1.63 W^{0.75}$, to estimate an individual's basal metabolic rate (BMR in $\mathrm{kJ} /$ day) as a function of its fat-free body mass ( $W$ in $\mathrm{g}$ ).

Since individuals were trapped soon after juveniles were weaned, juveniles and reproductive adult females had probably not accumulated significant amounts of fat (Rickart 1982; Kilgore and Armitage 1978). Body mass estimated at capture for these individuals, therefore, probably represents fat-free mass. Males and non-reproductive females $(N=33)$, on the other hand, probably had accumulated significant amounts of fat by the time juveniles were weaned and calculations of their BMR are probably overestimates.

I estimated average daily energy expenditure as a multiple of BMR. This estimate was used for all 109 individuals, and should include all components of metabolism, including locomotion, apparent specific dynamic action, and the potential contribution of specific dynamic action to basal metabolism (Karasov 1981). The coefficient of BMR was calculated from the mean of daily energy expenditure presented in other studies. Total metabolic cost $\left(Q_{M}\right)$ was estimated to be $2.79 \pm 0.84$ (S.D.) $\times$ BMR $(N=7)$ (Hudson and Deavers 1973; Morhardt and Gates 1974; Morhardt 1975; Schitoskey and Woodmansee 1978; Wang 1979; Karasov 1981; Kenagy 1987). This method only accounts for individual variation in metabolic rate due to body mass.

(d) Energy for fat storage $\left(Q_{H}\right)$. Since ground squirrels hibernate/estivate for 8 months of the year, they must store fat to survive hibernation. Different sex-age classes accumulate fat over different periods of time (Rickart 1982, Zegers and Williams 1977, Kilgore and Armitage 1978). I computed an individual's energy requirements for hibernation as an average daily energy requirement $\left(Q_{H}\right)$ that must be met to achieve the accumulation of fat necessary to survive hibernation. I also estimated daily hibernation energy requirements as a multiple of BMR for each individual.

The average daily energy intake during the active season necessary to meet metabolic costs during the hibernation season (including torpor and arousals) can be computed as:

$Q_{H}=\frac{(365-D) r B}{D c}$

for adult males, non-reproductive adult females, and yearlings and

$Q_{H}=\frac{(365-D) r B}{(D-L) c}$ for juveniles and adult females that raised litters. In these equations, $D$ is the number of days in the active season for the sex-age class, $L$ is the number of days of gestation and lactation during which juveniles do not feed and reproductive adult females do not store fat. $B$ is basal metabolism during the active season, $r$ is the ratio of metabolism during the hibernation season to basal metabolism during the active season, and $c$ is the conversion efficiency of energy in excess of metabolism $\left(Q_{D E}-Q_{M}\right)$ into fat. Wang (1979) estimated $r$ to be 0.278 , and Kilgore and Armitage (1978) estimated $c$ to be 0.245 . At my study site, the maximum number of days in the active season averages 110 , although males typically are active only for 87 , and gestation and lactation last 55 days. Consequently, I computed $Q_{H}$ to be 3.60 $\times$ BMR for adult males, $2.74 \times$ BMR for yearlings and nonreproductive adult females, and $5.26 \times \mathrm{BMR}$ for juveniles and reproductive adult females. Since these calculations are expressed as multiples of BMR, they only account for individual variation in requirements due to body mass.

\section{Physiological efficiency}

Deviators might compensate for their potentially reduced energy intake through greater physiological efficiency of processing ingested food. I determined whether individuals differed in their assimilation and conversion efficiency of ingested food. I recaptured a group of 9 adult females for which I had previously determined their deviation from an optimal diet. Each squirrel was kept in a $15 \times 15 \times 46 \mathrm{~cm}$ cage and fed measured ad libitum amounts of fresh cut alfalfa (Medicago sativa, a common ground squirrel food at my sites) for five days (=one trial). Trials were repeated three times successively.

Food intake (g dry mass) and fecal deposition ( $\mathrm{g}$ dry mass) were determined for each individual. Food intake was determined by subtracting the amount of uneaten food from the amount presented during the trial. All feces deposited by an individual were collected. Food and feces removed were dried at $60^{\circ} \mathrm{C}$ for $48 \mathrm{~h}$ and weighed. Water content of presented food was determined by drying alfalfa samples immediately after they were cut. A conversion factor (wet/ dry mass) was used to calculate the dry mass of food presented.

Growth was determined by weighing individuals with a spring scale to the nearest $0.5 \mathrm{~g}$ before and after the trial. Individuals were starved for $12 \mathrm{~h}$ prior to a trial (overnight) to clear the digestive tract and weighed in the morning before food was presented. Food was removed at the end of the fifth day of the trial and individuals were weighed again the following morning. This technique reduced the contribution of ingested food to body mass. Pre-trial starvation probably had little effect on 5 day estimates of assimilation and conversion efficiency, but, in any case, effects would be experienced equally among all individuals in the trial. Assimilation efficiency was computed as 1 - (dry fecal mass/ dry mass consumed). Net conversion efficiency of assimilated energy was computed as mass gained/ (dry mass consumed $\times$ assimilation efficiency).

\section{Components of fitness}

In any study of the fitness consequences of behavior, estimates of lifetime reproductive success for individuals are preferred, i.e. the total number of offspring reaching age 1 in a parent's lifetime. However, such complete estimates 
could not be obtained for ground squirrels during the period of the study (Michener 1980, Dobson and Kjelgaard 1985a, b). Instead, I measured three important short-term components of fitness: (1) average daily growth rate, (2) yearly survivorship, and (3) litter size.

(a) Growth rate. I measured the change in body mass over the interval 1 June to 1 July by re-trapping as many of the 109 individuals as possible ( 15 adults, 19 juveniles). Consequently, daily growth rates for each individual were computed as averages over the same 30 day period, since juvenile emergence dates varied little between years ( \pm 3.3 days).

(b) Survivorship. Yearly survivorship was measured by determining the presence/absence of 46 of the 109 individuals on the study sites ( 22 juvenile females and 24 adults) from year to year. Juvenile males were excluded from the analysis of survivorship because they typically disperse as yearlings. Adults and juvenile females, however, appear to be sedentary, i.e. remain on the colony for several years. (Murie and Harris 1978; Michener 1977, 1979a; Boag and Murie 1981; Festa-Bianchet and King 1984; Dobson and Kjelgaard 1985a).

Tagging may have increased the mortality of individuals (e.g. from predation, infection), but the effects of tagging were likely to be distributed equally among all individuals (Boag and Murie 1981; Dobson and Kjelgaard 1985a, b). Therefore, mortality due to tagging probably does not affect the conclusions of this study.

(c) Litter size. A total of 28 adult fernales were trapped 3-10 days prior to weaning of juveniles. All females with swollen nipples were considered to be lactating. Juveniles were captured within one week of emergence and assumed to be the weaned litter of the lactating female in whose burrow system they were captured. This technique has been used successfully in many previous studies (e.g. Armitage 1977; Michener 1980; Murie and Harris 1984; Dobson and Kjelgaard $1985 \mathrm{a}, \mathrm{b})$.

\section{Results}

The necessary foraging parameters to compute average daily deviation from an optimal diet and digestible energy intake $\left(Q_{D E}\right)$ were measured for each of the 109 individuals. The equations used in determining the foraging constraints are presented in Table 1, including the parameters computed on the basis of individual body mass. As an example, the parameters for two juveniles are presented (Table 2): one which deviates from its optimal diet in favor of dicots, and one which deviates in favor of monocots. These individuals were used to demonstrate how deviation from an optimal diet and daily energy intake are calculated. For other examples of individuals, see Ritchie (1988). The observed diets of the two individuals are similar $(35.6 \%$ and $30.4 \%$ monocots, respectively) but this is coincidental; observed diets of individuals ranged from 0-82\% monocots (Ritchie 1988).

Each of these parameters is estimated, so there is some variance in the predicted diet and computed daily energy intake for each individual. However, by using a Monte Carlo simulation technique to generate confidence intervals for the predicted diet, I show that this variance does not subsume individual differences in foraging ability (Ritchie
1988). By extension, parameter variation does not subsume differences in daily energy intake among individuals. Furthermore, no correlation exists $\left(r^{2}=0.02, P>0.56\right)$ between variance in model parameters and deviation from an optimal diet (Ritchie 1988). This result shows that optimal individuals are not simply those whose foraging parameters were measured more precisely.

\section{Energy intake and optimal foraging}

Energy budgets were calculated for each of 109 individuals. The linear programming models for the two example individuals are provided (Fig. $1 \mathrm{a}$, b), using the parameters in Table 2. As discussed in the Methods, the foraging constraints of individuals' linear programming models were used to estimate digestible energy intake $\left(Q_{D E}\right)$ from Eqn. $2 \mathrm{a}$ or $2 \mathrm{~b}$ and surplus energy intake $\left(Q_{S E}\right)$ from Eqn. 1 (see Methods). This method calculates the maximum potential daily surplus energy intake for an individual in early June.

Energy intake of individuals that deviate from their optimal diet in favor of dicots is limited by digestive capacity. These individuals cannot use all of their activity time to feed, and consequently must reduce the proportion of their activity time they actually spend feeding. The proportion of activity time spent feeding can be predicted from an individual's linear programming model (Fig. 1). The observed proportion of activity time actually spent feeding could be measured for only nine individuals that deviated from their optimal diet in favor of dicots (Ritchie 1988). For these 9 individuals, predicted and observed proportions of activity time spent feeding are highly correlated (Fig. 2) $\left(r^{2}=0.95\right.$, $N=9, P<0.0001$ ). This suggests that individuals are consuming the maximum possible energy, given their observed diet proportions, and supports the use of the computed energy intake (from Eqns. 2a or $2 b$ ) as an estimate of daily energy intake for all individuals.

Energy intake did not appear to change with energy demands. For six reproductive adult females, calculated di-

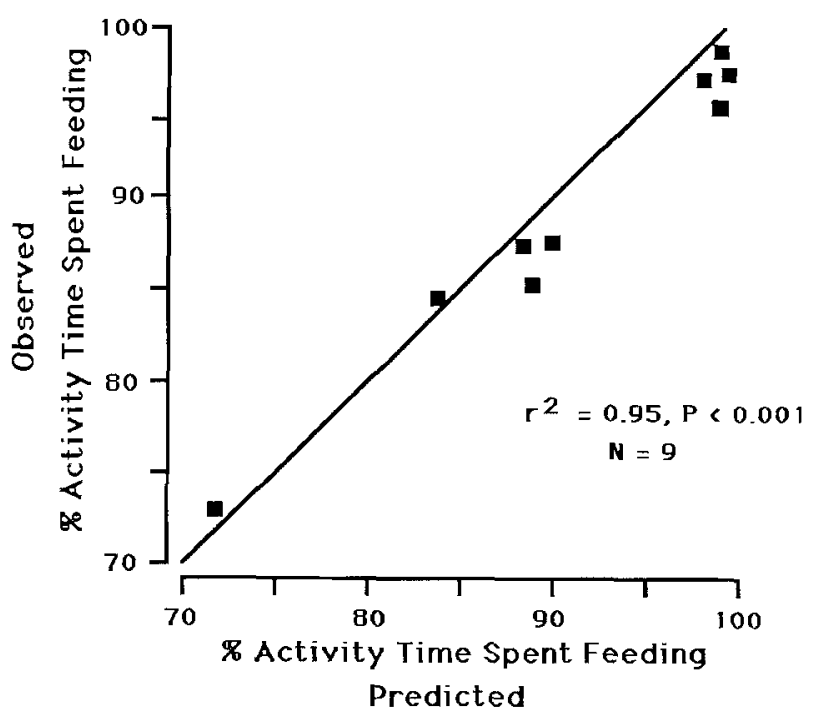

Fig. 2. Individuals' observed proportion of activity time spent feeding vs. that predicted from their linear programming models. Data are from individuals for which the necessary observations to determine actual feeding time could be obtained, and which deviated from their optimal diet in favor of dicots. The diagonal line represents perfect agreement 


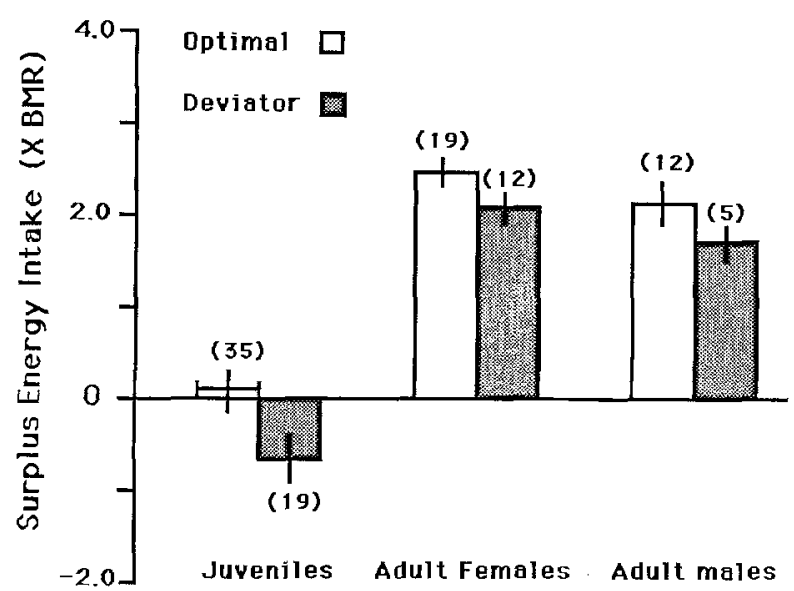

Fig. 3. The mean ( \pm S.E.) estimated surplus energy intakes for the two types of foragers, optimal (open bars) and deviator (stippled bars), shown separately for juveniles, adult females, and adult males. Energy intakes are expressed as multiples of basal metabolic rate to account for individual differences in body size. All differences are significant (see text)

gestible energy intake during lactation was significantly correlated with that during post-weaning periods 20 days later $\left(r^{2}=0.90, P<0.01\right)$. Furthermore, the slope of this regression line was not significantly different from one (slope $=0.922 \pm 0.318, t=0.24, P>0.20$ ), indicating that energy intake did not decline after weaning. Finally, the proportion of activity time spent feeding was measured for 4 of these females, and was never less than $90 \%$.

Surplus energy intake was compared between "optimal" and "deviating" foragers (Fig. 3). Mean energy intake for optimal foragers was significantly greater than that for deviators among adult males $(t=1.95, N=17, P<0.05$, onetailed), adult females ( $t=2.97, N=31, P<0.01$, one-tailed), and juveniles $(t=3.103, N=54, P<0.001$, one-tailed). Assuming that energy requirements are, on average, the same for optimal and deviator foragers of a given body size, optimal foragers have greater surplus daily energy intake than deviators. There was no difference in the average foraging parameters (body size, activity time, cropping rates, and digestive capacity) of optimal and deviating foragers (Table 3). As a result, the difference in energy intake between optimal and deviating foragers is due only to the difference in individuals' ability to select their optimal diets. Since an individual's deviation from its optimal diet is preserved across foraging environments (e.g. food abundance, social environment) and time within an active season (Ritchie 1988), differences among individuals in daily energy intake are likely to be preserved as well.

Assimilation efficiency does not differ significantly among individuals (Table 4) $(F=1.53, N=9, P>0.20)$ and does not correlate with foraging ability $(r=0.173, P>0.20)$. Conversion efficiency, however, varies significantly among individuals $(F=16,3, P<0.001)$ and is marginally correlated with foraging ability $(r=-0.556, P=0.17)$. However, the slope of this regression line is negative, suggesting that deviators may have either higher metabolic rates, or lower conversion efficiency of energy in excess of metabolism. Deviators, therefore, do not appear to compensate for their lower energy intake through increased physiological efficiency, and, in fact, may exhibit lower efficiency.

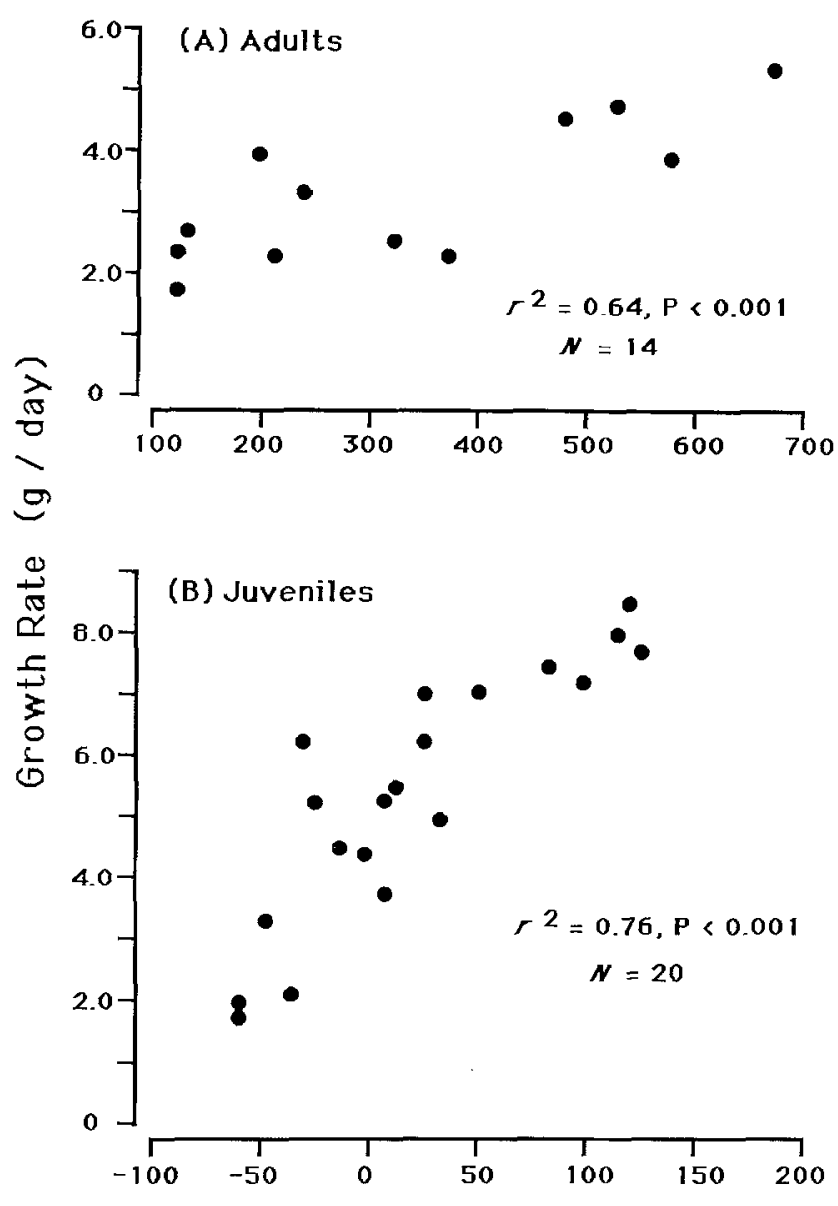

Surplus Energy Intake (kJ / day)

Fig. 4A, B. The relationship between average daily post-weaning growth rate and surplus daily energy intake for $(\boldsymbol{A})$ adults (males and females combined) and (B) juveniles

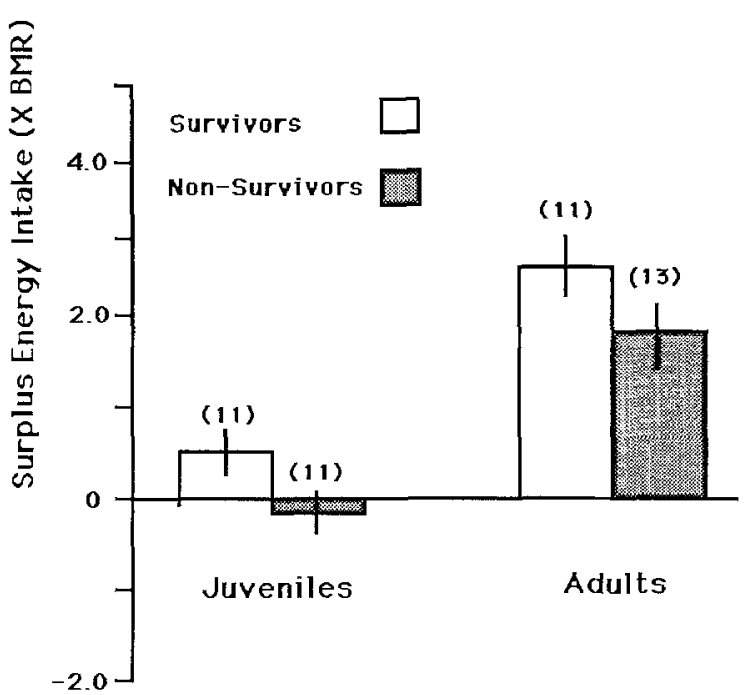

Fig. 5. Mean ( \pm S.E.) surplus daily energy intakes for individuals which survived over one winter (open bars) and those which did not (hatched bars). Energy intakes are presented as multiples of basal metabolic rate to account for differences in individual body size. Data are shown separately for adults and juveniles. All differences are significant (see text) 


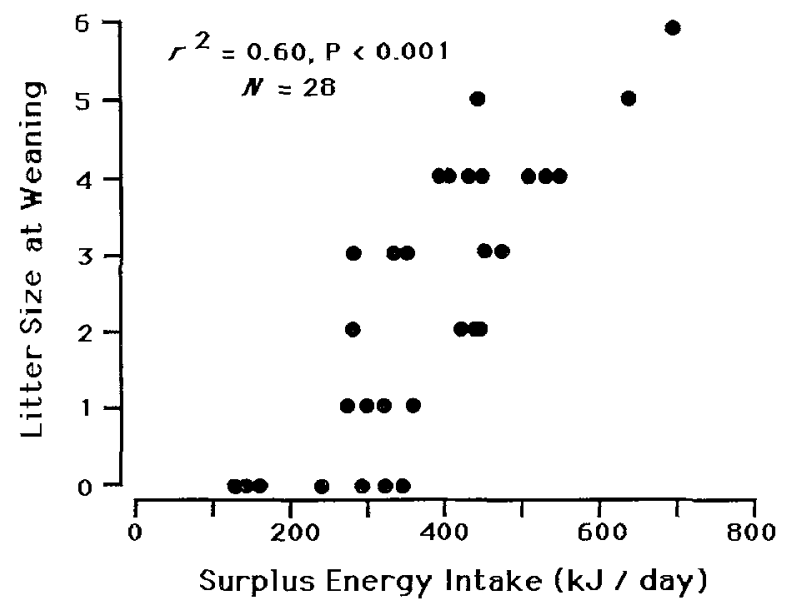

Fig. 6. The relationship between litter size at weaning and surplus daily energy intake for adult females which were lactating when first captured. The regression equation is $y=0.0117 x-2.11$

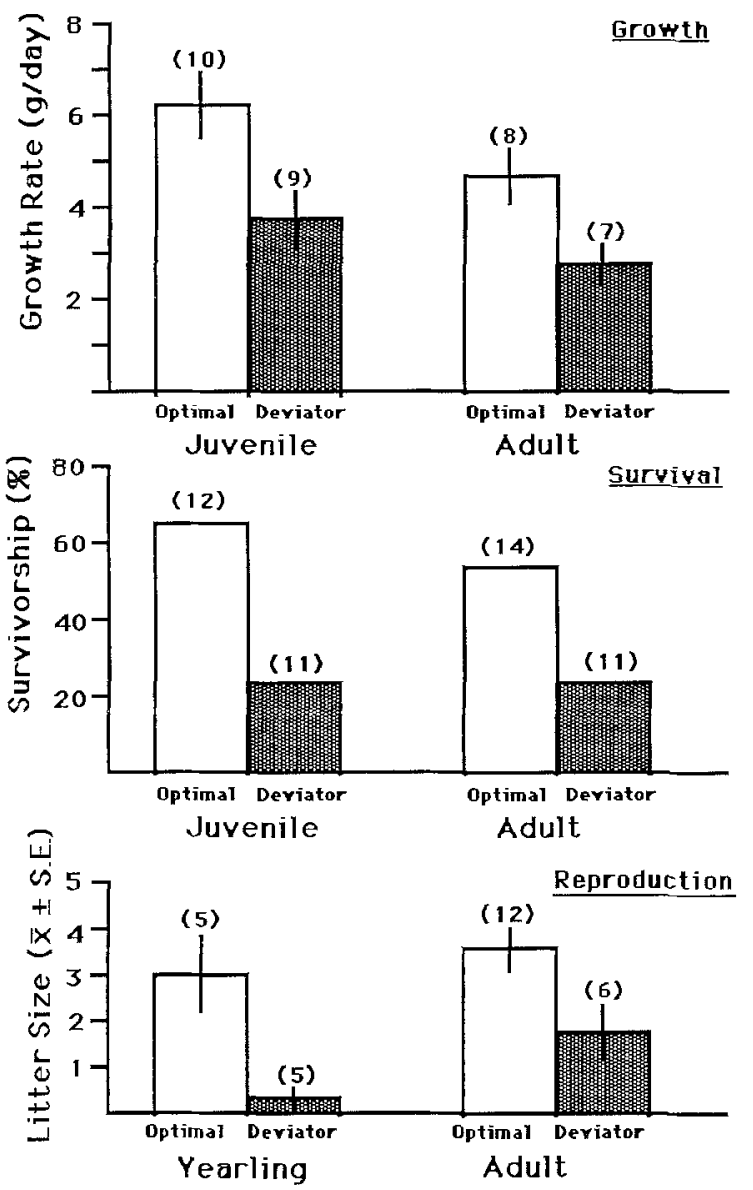

Fig. 7. Three fitness components, average daily growth, yearly survivorship and litter size, are compared for optimal (open bars) and deviator (stippled bars) foragers. Data for growth and survivorship are shown separately for juveniles and adults, and litter sizes are shown separately for yearlings and adults. Means for growth and litter size are presented with standard errors. Sample sizes are in parentheses. For statistical comparisons, see text

\section{Energy intake and fitness}

Three fitness compounts of individuals were related to their calculated surplus energy intake. Daily growth rate appears to increase with energy intake for both adults (males and females combined) and juveniles (Fig. 4A, B) $\left(r^{2}=0.64\right.$, $P<0.01, N=14 ; r^{2}=0.76, P<0.001, N=20$; respectively). Adults and juveniles that survive from one year to the next have significantly greater calculated energy intake than those that do not survive (Fig. 5) (Adults: $t=3.79$, $P<0.0001$; Juveniles: $t=3.27, P<0.001)$. Adults of both sexes were combined for survivorship analysis because sample sizes were too small to consider each sex separately. Finally, the weaned litter size of lactating females increases significantly with calculated surplus energy intake (Fig. 6) $\left(r^{2}=0.72, \quad P<0.001, N=28\right)$. These fitness components, therefore, appear to be strongly associated with increased energy intake.

Growth rate and litter size were compared with absolute energy intake because growth and offspring production increase incrementally with energy intake. On the other hand, survival is presumably dependent on acquiring energy above some threshold, i.e., once the threshold is achieved, survivorship does not increase (or only at a much slower rate). This threshold is likely to be a function of metabolism, e.g. acitvity and hibernation energy requirements. Therefore, comparing multiples of BMR for survivors versus non-survivors factors out metabolic body size and is appropriate.

I compared fitness components of individuals classified as "optimal" or "deviator" to determine if optimal foragers have greater fitness (Fig. 7). Growth rates are significantly greater for both optimal juveniles $(t=3.11, \quad N=19$, $P<0.001)$ and adults $(t=4.49, N=15, P<0.001)$. Survivorship was significantly greater for "optimal" adults (Fisher's Exact test, $P=0.036$ ) and marginally so for juveniles $(P=0.077)$. Finally, average litter size was significantly greater for both optimal yearlings $(t=5.98, N=10$, $P<0.001)$ and adults age two or older $(t=2.14, N=21$, $P<0.025$ ). Therefore, optimal foragers appear to have greater growth, survival and reproduction.

\section{Discussion}

The results from this study can be used to answer three important questions: (1).Can the calculated difference in energy intake between optimal and deviating foragers explain their observed difference in survival and reproduction? (2) Is there evidence for alternative influences on reproductive success, e.g. predation? (3) What is the potential fitness advantage of being an optimal forager? The answers to these questions are important to the ecological and evolutionary significance of optimal foraging behavior.

\section{Energy intake and fitness}

The natural history of Columbian ground squirrels suggests that energy intake might be extremely important to their survival and reproduction (Manville 1959; Murie and Boag 1984; Dobson and Kjelgaard 1985a, b). Ground squirrels at my site appear to hibernate/estivate for 8 months of the year (July-March), presumably because they are unable to meet above-ground energy or water requirements during this period (Blake 1972; Hudson and Deavers 1973; Davis 1976; Bintz 1984; Belovsky and Ritchie 1990).

Adult females at my study site, as a result, have a short active period in which to mate, raise a litter, and store sufficient fat for successful hibernation during the following winter. Males spend energy finding and defending mates as well as storing fat for later hibernation (Murie and Harris 
Table 3. Average parameters of the linear programming model for adult males, adult females, and juveniles. Data are shown separately for "optimal" and "deviator" individuals

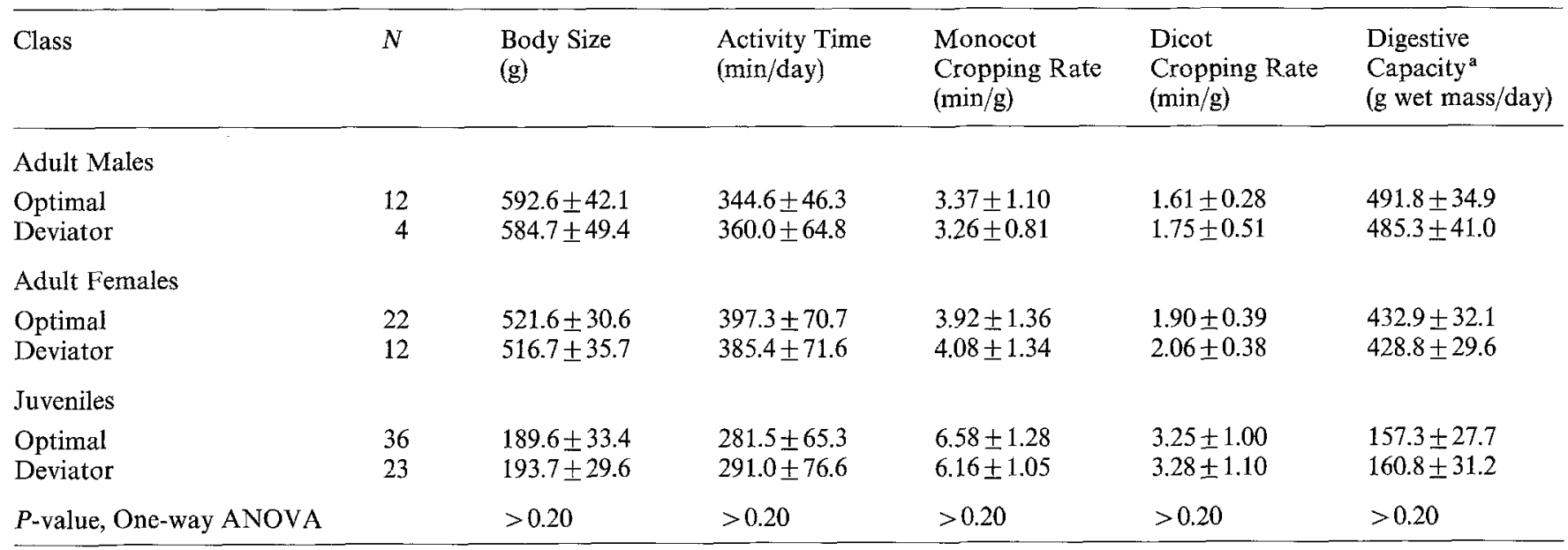

a Food bulk (g wet mass/g dry mass) was assumed to be equal for all individuals: 1.64 for monocots, 2.67 for dicots, (Belorsky 1986a)

1978; Dobson 1983; Michener 1983; Balph 1984). Juveniles and reproductive adult females have even fewer days than other adults in which to grow and store fat for hibernation (Zegers and Williams 1977; Michener 1979b; Dobson and Kjelgaard $1985 \mathrm{a}$, b). It is not surprising, therefore, that several components of fitness are related to calculated energy intake.

Some studies suggest that energy intake varies with energy demand (e.g. Millar 1975; Karasov 1985; Kenagy 1987). In my study, however, an individual's energy intake at a given time appears to be set by its foraging constraints, which are independent of energy demands, because (1) the observed proportion of activity time spent foraging by individuals agrees with that predicted by their linear programming model (Fig. 2), and (2) adult females' energy intake did not decline after weaning. These results also concur with the observation that ground squirrels are energy maximizers throughout the active season (Belovsky and Ritchie 1990).

Survivorship in many ground squirrel populatons appears to be related to fat storage for hibernation (Davis 1976; Zegers and Williams 1977; Morton and Sherman 1978; Rickart 1982; Michener 1983; Dobson and Kjelgaard $1985 \mathrm{a}, \mathrm{b})$. Individuals with faster growth rates may store more fat for hibernation during the active season. Since growth rate increases with calculated energy intake (Fig. 4), this may explain why individuals with greater energy intake were more likely to survive.

A different way to view the problem is that individuals must exceed some threshold of energy intake, i.e. hibernation energy requirements, to survive over winter. Thus, ground squirrels with surplus energy intake $\left(Q_{\text {SE }}\right)>0$ should have sufficient fat for hibernation and survive, and those with $Q_{S E}<0$ should not. Using the observed means and standard deviations for surplus energy intake (Fig. 3), I constructed standard normal distributions of energy intake for each age class and foraging classification. The proportion of individuals with $Q_{S E}>0$ can be estimated using the $z$ statistic and a standard normal distribution: this represents the proportion of individuals expected to survive.

Using this method, I predicted survivorship for optimal and deviating individuals with the data in Fig. 3. For juve- niles, predicted survivorship values of $51 \%$ and $31 \%$ for optimal and deviator forages, respectively, correspond well with their respective observed survivorship values (Fig. 7) of $66 \%$ and $30 \%$ (Goodness of Fit, optimal: $X^{2}=1.46$, $P>0.20$; deviator: $\left.X^{2}=0.003, P>0.90\right)$. The difference in mean digestible energy intake between optimal and deviating foragers is $0.63 \times \mathrm{BMR}$, or only $7.4 \%$ of the total digestible energy intake for optimal foragers. Consequently, survivorship of juveniles appears to be highly sensitive to their energy intake.

A close link between energy intake and survival was not observed for adults. Predicted survivorships of $98 \%$ for optimal foragers and $92 \%$ for deviators were much greater than observed survivorship values of $55 \%$ and $22 \%$, respectively (Fig. 7). A similar pattern was found by Murie and Boag (1984). This suggests that other factors (e.g. additional energy costs, predation) may determine adult survivorship (but see below).

Litter size also appears related to the ability of females to meet reproductive costs through energy intake (Fig. 6). The data suggest that there is some threshold of surplus energy intake which must be exceeded for a female to wean a litter successfully. Furthermore, litter size appears to be sensitive to average daily energy intake of females.

Optimal foraging theory assumes that optimal foragers achieve superior fitness solely through their diet choice and not from some other character which might be associated with optimal foraging behavior, e.g. physiological efficiency, or body size (Pyke 1984; Stephens and Krebs 1986). My results suggest that the foraging parameters for average optimal and deviating foragers are not different (Table 3). Therefore, optimal and deviating foragers differ in their calculated energy intake primarily because they differ in the ability to select their optimal diet.

Individuals, however, sometimes show considerable variation in assimilation and conversion efficiency of food (Hayes and Eisen 1979; Baker et al. 1984; Garton 1984). Therefore, deviators could potentially compensate for their reduced energy intake through greater digestibility (assimilation efficiency) or conversion efficiency. While no strong relationships between foraging ability and physiological efficiency were found, my results indicate that deviators may 
Table 4. Assimilation efficiencies and conversion efficiencies (g live mass gained/g food assimilated) of assimilated food for 9 adult females fed alfalfa (Medicago sativa) leaves ad libitum. Each individual's deviation from an optimal diet is also presented

\begin{tabular}{llll}
\hline Individual & $\begin{array}{l}\text { Assimilation } \\
\text { Efficiency }\end{array}$ & $\begin{array}{l}\text { Conversion } \\
\text { Efficiency }\end{array}$ & $\begin{array}{l}\text { Deviation } \\
\text { From } \\
\text { Optimal }\end{array}$ \\
& $(\%)$ & $(\%)$ & $\begin{array}{l}\text { a } \\
(\%)\end{array}$ \\
\hline 0-0 & $65.3 \pm 5.9^{\mathrm{b}}$ & $23.3 \pm 7.0$ & 0.9 \\
0-W & $70.1 \pm 3.7$ & $8.8 \pm 1.4$ & 6.7 \\
W-W & $65.3 \pm 5.5$ & $10.6 \pm 3.5$ & 4.5 \\
W-Y & $67.5 \pm 6.3$ & $20.4 \pm 1.2$ & 2.5 \\
0-/ & $69.6 \pm 4.8$ & $14.7 \pm 0.5$ & 3.5 \\
0-Y & $70.6 \pm 3.5$ & $21.0 \pm 2.8$ & 1.2 \\
0-BW & $71.6 \pm 5.9$ & $22.4 \pm 3.1$ & 4.9 \\
W-L & $70.2 \pm 2.8$ & $16.9 \pm 1.6$ & 0.5 \\
0-L & $73.2 \pm 5.5$ & $17.9 \pm 0.8$ & 18.3 \\
One-Way ANOVA & $P>0.20$ & $P<0.001$ &
\end{tabular}

a See text

b Means and standard deviations from 3 trials for each individual

exhibit lower physiological efficiency (Table 4). A more detailed study would be necessary to determine whether this potential difference in physiological efficiency can account for the observed difference in fitness components.

\section{Predation}

While energy/nutrient intake appears to strongly affect survival and reproduction, predation might also be important. Predation by badgers (Taxidea taxus), long-tailed weasels (Mustela frenata) and several large raptors may reduce survivorship of adults and weaned juveniles during the active or hibernation season (Manville 1959; Craighead and Craighead 1956; Luttich et al. 1970; Slade and Balph 1974; Dobson and Kjelgaard 1985b).

The results of this study, however, cannot be readily attributed to predation. First, predation rates (successful attacks per day) on squirrels active above-ground accounted for less than $6 \%$ of yearly mortality in my populations (G.E. Belovsky; M.E. Ritchie; J.B. Slade, unpublished work). Second, overwinter survivorship of juveniles corresponds closely to that predicted by energy intake. If predation was important, observed survivorship should be lower than that predicted by energy intake, and this is not observed (see above).

Predation is also unlikely to account for the difference in survivorship of optimal and deviating foragers. To generate the observed pattern, predators would have to preferentially select deviators as prey. Given that deviators were no less active than optimal foragers (Table 2) and occupied similar microhabitats (M.E. Ritchie unpublished work), there is no apparent reason why deviators should be at greater predation risk. Consequently, predator preference for deviators seems unlikely, unless deviators are in poor condition and are more easily captured. Even so, energy intake would still appear to be important to survivorship through its effect on general body condition, rather than fat accumulation.

\section{Fitness advantage of optimal foraging}

The observed difference in growth rate, survivorship, and litter size between optimal and deviating foragers (Fig. 7)
Table 5. Partial life tables for (A) optimal and (B) deviator females (A) Optimal females

\begin{tabular}{lllll}
\hline Age & $q_{x}$ & $s_{x}$ & $r_{x}$ & \\
\hline 0 & 0 & 1.0 & 0 & \\
1 & 0.66 & 0.66 & 0.75 & $\begin{array}{l}\text { Reproductive } \\
\text { Success: } \\
2\end{array}$ \\
3 & 0.61 & 0.40 & 0.85 & $\sum_{x=0}^{3} s_{x} r_{x}=1.039$ \\
\hline
\end{tabular}

(B) Deviating females

\begin{tabular}{lllllll}
\hline Age & $c_{x}$ & $q_{x}^{*}$ & $\hat{s}_{x}$ & $r_{x}^{*}$ & $\hat{r}_{x}$ & \\
\hline 0 & 0 & 0 & 1.0 & 0 & 0 & \\
1 & 0.38 & 0.30 & 0.30 & 0.05 & 0.32 & $\begin{array}{l}\text { Reproductive } \\
\text { Success: }\end{array}$ \\
2 & 0.61 & 0.22 & 0.11 & 0.41 & 0.68 & $\sum_{x=0}^{3} \hat{s}_{x} \hat{r}_{x}=0.175$ \\
3 & 0.76 & 0.22 & 0.05 & 0.41 & 0.74 & \\
$\hat{s}_{x}=\left[q_{x}^{*}\left(1-c_{x-1}\right)+q_{x}\left(c_{x-1}\right)\right] \hat{s}_{x-1}$ & & & \\
$\hat{r}_{x}=\left[r_{x}\left(1-c_{x}\right)+r_{x} c_{x}\right]$
\end{tabular}

Terms:

$c_{x} \quad=$ proportion of original deviators converted to optimal

$q_{x} \quad$ = yearly survivorship of optimal foragers

$q_{x}^{*} \quad=$ yearly survivorship of deviators

$s_{x} \quad=$ survivorship from birth of optimal foragers

$\hat{s}_{x} \quad=$ survivorship from birth of original deviators

$r_{x} \quad=$ production of female yearlings by optimal foragers

$r_{x}^{*} \quad=$ production of female yearlings by deviators

$\hat{r}_{x} \quad=$ production of female yearlings by original deviators

age $(x)=$ years from date of birth

suggests that optimal foragers may possess a large fitness advantage over deviators. Previous presentations of optimal foraging theory and the many empirical tests of that theory have assumed this (Pyke 1984; Stephens and Krebs 1986). No previous studies, however, have examined whether this assumption is valid.

To summarize the data on fitness components and provide a crude estimate of individuals' reproductive success up to age three, I constructed partial life tables for optimal and deviating females which reproduced at ages $\geq 1$ (Table $5 \mathrm{a}, \mathrm{b})$. These tables compare the average number of yearling female offspring produced by an individual female in her first three years (my best measure of reproductive success). The tables were constructed only through age three because I was unable to accurately distinguish individuals older than age two from body size measurements (Ritchie 1988) and could not accurately account for mortality of adults older than age three.

Mortality occurs primarily over winter, so yearly survivorship to age $x$ was measured from the previous summer to the current summer $x$. The number of yearling females produced was measured during the current summer $x$ after mortality. For optimal foragers, reproductive success through age three can be calculated as $\sum_{x=0}^{3} s_{x} r_{x}$, where $s_{x}$ is survivorship of optimal foragers from birth to age $x$, and $r_{x}$ is the average litter size for an optimal female of age $x$ multiplied by one-half (to account for males) and average 
(optimal and deviators combined) juvenile survivorship (Clutton-Brock 1988). Note that this measure is not net reproductive rate $\left(R_{o}\right)$ in standard life tables because survivorship of offspring is included.

Measuring reproductive success for deviators is more complicated. Individuals born as deviators gradually improve in their foraging ability over their lifetime (Ritchie 1988). From the regression of deviation in one year $(y)$ on deviation the previous year $(x)\left(y=0.65 x+0.56, r^{2}=0.83\right.$; Ritchie 1988), deviators improve approximately $35 \%$ per year. Based on the observed frequency distribution of deviations for juveniles (approximately a negative-exponential) (Ritchie 1988), this magnitude of reduction in deviation results in $38 \%$ of deviators becoming re-classified as optimal foragers each year as a cohort grows older. I used the parameter $c_{x}$, to keep track of how many juvenile deviators would become optimal by age $x$.

Survivorship of original deviators at age $x, \hat{s}_{x}$, is therefore a function of $q_{x}^{*}$, the yearly survivorship of deviators to age $x, c_{x-1}$, the proportion of deviators that had become optimal by the end of the previous summer, and $q_{x}$, the yearly survivorship of optimal foragers to age $x$. Likewise, $\hat{r}_{x}$, the number of yearling females produced by deviators at age $x$, is a function of $c_{x}$, the proportion of deviators converted to optimal at the current age $x, r_{x}^{*}$, the production of yearling females by deviators at age $x$, and $r_{x}$, the yearling females produced by optimal foragers at age $x$. The formulas for calculation and empirical values are presented in Table 5 . Reproductive success through age 3 for original deviators is $\sum_{x=0}^{3} \hat{s}_{x} \hat{r}_{x}$.

Based on these calculations, optimal females appear to have nearly six times the reproductive success of deviators by age three (Table 5). This result suggests that if foraging behavior is a heritable trait, natural selection may strongly favor the ability to choose an optimal diet. Two important questions arise at this point: (1) is foraging ability genetically heritable, and (2) how are deviators maintained in the population in the face of such strong selection? Proper heritability experiments must be conducted, however, before these questions can be answered.

I was able to demonstrate a fitness advantage for optimal foraging behavior for two reasons: (1) energy appears to be an important "currency" for fitness and (2) the ability to select an optimal diet appears to be independent of other characters that might determine energy intake (Table 2). Similarly, detection of the natural selection of foraging behavior in other organisms requires that the "currency" for fitness must be correctly identified, since it may not always be energy (Schoener 1971; Pyke 1984).

\section{Conclusion}

This study shows that the ability to select an optimal diet has a very strong impact on the fitness of Columbian ground squirrels. Energy intake appears to be a very important factor determining ground squirrel survival and reproduction. Consequently, optimal individuals appear to have a very strong fitness advantage over deviators because of their greater energy intake. This confirms an underlying assumption of optimal foraging theory and suggests that optimal foraging behavior, if heritable, is potentially subject to natural selection (Pyke 1984; Stephens and Krebs 1986).
Acknowledgements. I thank G.E. Belovsky, J.S. Diana, J.O. Murie, O.J. Schmitz, P.E. Smouse, P.W. Webb, and several anonymous reviewers for critically reading several drafts of this manuscript. I thank J. Brady, L. Evans, R. Jensen, and W. Pearson for access to their land near the National Bison Range. I greatly appreciated the help of field assistants R. Henderson, D. McCullough, S. Wall, and $\mathrm{J}$. Richter. The work was supported by NSF grant BSR 8307352 to G.E. Belovsky, a Doctoral Dissertation Improvement grant BSR - 8501040 to G.E. Belovsky and the author, Grants-inAid from Sigma Xi, the Scientific Research Society, in 1983 and 1985, and a Rackham Predoctoral Fellowship from the University of Michigan.

\section{References}

Armitage KB (1977) Social variety in the yellow-bellied marmot: a population - behavioral system. Anim Behav 25:585-593

Ayala FJ (1967) Dynamics of populations. II. Factors affecting population growth and population size in Drosophila pseudoobscura and Drosophila melanogaster. Ecology 48:67-78

Baker RL, Cox EH, Carter AH (1984) Direct and correlated responses to selection for weaning weight, post-weaning weight gain, and six week weight in mice. Theor Appl Genet 67:113122

Balph DA (1984) Spatial and social behavior in a population of Uinta ground squirrels: interrelations with climate and annual cycle. In: Murie JO, Michener GR (eds) The biology of grounddwelling squirrels. Univ Nebraska Press, Lincoln pp 326-352

Belovsky GE (1978) Diet optimization in a generalist herbivore: the moose. Theor Pop Biol 14:105-134

Belovsky GE (1984a) Herbivore optimal foraging: a test of three models. Am Nat 124:97-115

Belovsky GE (1984a) Snowshoe hare optimal foraging and its implications for population dynamics. Theor Pop Biol 25:235-264

Belovsky GE (1986a) Optimal foraging and community structure: implications for a guild of generalist grassland herbivores. Oecologia 70:35-62

Belovsky GE (1986b) Generalist herbivore foraging and its role in competitive interactions. Am Zool 26:51-69

Belovsky GE, Ritchie ME (1990) Geographical and seasonal variation in foraging of Columbian ground squirrels. Oecologia (in press)

Bintz GL (1984) Water balance, water stress, and the evolution of seasonal torpor in ground-dwelling sciurids. In: Murie JO, Michener GR (eds) The biology of ground-dwelling squirrels. Univ Nebraska Press, London pp 142-166

Blake BH (1972) The annual cycle and fat storage in two populations of golden-mantled ground squirrels. J Mamm 53:157-167

Boag DA, Murie JO (1981) Population ecology of Columbian ground squirrels in southwestern Alberta. Can J Zool 59:22302240

Christiansen FB, Bundgaard J, Barker JSF (1977) On the structure of fitness estimates under post-observational selection. Evolution 31:843-853

Clutton-Brock TH (ed) (1988) Reproductive success : studies of individual variation in contrasting breeding systems. Univ Chicago Press, Chicago

Craighead JJ, Craighead FC (1956) Hawks, owls, and wildlife. Stackpole, Harrisburg, Pennsylvania, USA

Davis DE (1976) Hibernation and circannual rhythms of food consumption in marmots and ground squirrels. Q Rev Biol 51:477514

Dobson FS (1983) Agonism and territoriality in the California ground squirrel. J Mamm 64:218-225

Dobson FS, Kjelgaard JD (1985a) The influence of food resources on life history in Columbian ground squirrels. Can $J$ Zool 63:2105-2109

Dobson FS, Kjelgaard JD (1985b) The influence of food resources on population dynamics in Columbian ground squirrels. Can J Zool 63:2095-2104 
Elner RW, Hughes RN (1978) Energy maximization in the diet of the shore crab Carcinus maenas. J Anim Ecol 47:103-116

Endler JA (1986) Natural selection in the wild. Princeton University Press, Princeton, New Jersey, USA

Festa-Bianchet M, King WJ (1984) Behavior and dispersal of yearling Columbian ground squirrels. Can J Zool 62:161-167

Garton DW (1984) Relationship between multiple locus heterozygosity and physiological energetics of growth in the estuarine gastropod Thais haematoma. Physiol Zool 57:530-543

Goss-Custard JD (1977) Opitmal foraging and the size selection of worms by redshank (Tringa totanus), in the field. Anim Behav $25: 10-29$

Hayes JF, Eisen EJ (1979) Environmental maternal influences on body composition in mice selected for body weight. Theor Appl Genet 55:209-223

Hixon MA (1982) Energy maximizers and time minimizers: theory and reality. Am Nat 119:596-599

Hudson JW, Deavers DR (1973) Metabolism, pulmo-cutaneous water loss, and respiration of eight species of ground squirrels from different environments. Comp Biochem Physiol A 45:69100

Karasov WH (1981) Daily energy expenditure and the cost of activity in a free-living mammal. Oecologia 51:253-259

Karasov WH (1982) Energy assimilation, nitrogen requirement, and diet in free-living antelope ground squirrels, Ammospermophilus leucurus. Physiol Zool 55:378-392

Karasov WH (1985) Nutrient constraints in the feeding ecology of an omnivore in a seasonal environment. Oecologia 66:280 290

Kenagy GJ (1987) Energy allocation for reproduction in the goldenmantled ground squirrel. Symp Zool Soc Lond 57:259-273

Kilgore DL, Armitage KB (1978) Energetics of yellow-bellied marmot populations. Ecology 59:78-88

Kleiber M (1961) The fire of life. Wiley Press, New York

Krebs JR, Erichsen JT, Webber JI, Charnov EL (1977) Optimal prey selection in the great tit (Parus major). Anim Behav 25:3038

Krebs JR, Ryan JC, Charnov EL (1974) Hunting by expectation or optimal foraging? A study of patch use by chickadees. Anim Behav 22:953-964

Lack D (1966) Population studies of birds. Clarendon Press, Oxford, UK

Leslie PH, Tener TS, Vizuso M, Chitty H (1955) The longevity and fertility of the Orkney vole, Microtus orcadensis, as observed in the laboratory. Proc London Zool Soc 125:115-125

Luttich S, Rusch DH, Meslow EC, Keith LB (1970) Ecology of red-tailed hawk predation in Alberta. Ecology 51:190-203

Manville RH (1959) The Columbian ground squirrel in northwestern Montana. J Mamm 40:26-45

Michener GR (1977) Effect of climatic conditions on the annual activity and hibernation cycle of Richardson's ground squirrels and Columbian ground squirrels. Can J Zool 55:693-703

Michener GR (1979a) Spatial relationships and social organization of adult Richardson's ground squirrels. Can J Zool 57:125-139

Michener GR (1980) Differential reproduction among female Richardson's ground squirrels and its relation to sex ratio. Behav Ecol Sociobiol 7:173-178

Michener GR (1983) Spring emergence schedules and vernal behavior of Richardson's ground squirrels: why do males emerge from hibernation before females? Behav Ecol Sociobiol 14:29_ 38

Miller JM (1975) Tactics of energy partitioning in breeding Peromyscus. Can J Zool 53:967-976
Morhardt SS (1975) Use of climatic diagrams to describe microhabitats occupied by Belding ground squirrels and to predict rates of change of body temperature. pp 303-323 in Gates DM, Schmerl RB (eds) Perspectives in biophysical ecology. SpringerVerlag, New York, USA

Morhardt SS, Gates DM (1974) Energy-exchange analysis of the Belding ground squirrel and its habitat. Ecol Monogr 44: 17-44

Morton ML, Sherman PW (1978) Effects of a spring snowstorm on behavior, reproduction, and survival of Belding's ground squirrels. Can J Zool 56:2578-2590

Murie JO, Boag DA (1984) The relationship of body weight to overwinter survival in Columbian ground squirrels. J Mamm 65:688-690

Murie JO, Harris MA (1978) Territoriality and dominance in male Columbian ground squirrels (Spermophilus columbianus). Can J Zool 56:2402-2412

Murie JO, Harris MA (1984) The history of individuals in a population of Columbian ground squirrels: source, settlement and site attachment. In: Murie JO, Michener GR (eds) The biology of ground-dwelling squirrels. Univ Nebraska Press, Lincoln pp 353-374

Porter KG, Orcutt JD, Gerritsen J (1983) Functional response and fitness in a generalist filter feeder, Daphnia magna (Cladocera: Crustacea). Ecology 64:735-742

Pyke GH (1984) Optimal foraging theory: a critical review. Ann Rev Ecol Syst 15:523-575

Rickart EA (1982) Annual cycles of acitvity and body composition in Spermophilus twonsendii mollis. Can J Zool 60:3298-3306

Ritchie ME (1988) Individual variation in the ability of Columbian ground squirrels to select an optimal diet. Evol Ecol 2:232-252

Schitoskey F, Woodmansee SR (1978) Energy requirements and the diet of the California ground squirrel. J Wildl Manage 42:373-382

Schoener TW (1971) Theory of feeding strategies. Ann Rev Ecol Syst 2:369-404

Slade NA, Balph DF (1974) Population ecology of Uinta ground squirrels. Ecology 55:989-1003

Smith AD, Shandruk LJ (1979) Comparison of fecal, rumen, and utilization methods for ascertaining pronghorn diets. J Range Manage 32:275-279

Sparks DR, Malechek JC (1968) Estimating-percentage dry weight in diets using a microscopic technique. J Range Manage 21:264-265

Stephens DW, Krebs JR (1986) Foraging theory. Princeton University Press, Princeton, New Jersey, USA

Storr GM (1963) Estimation of dry-matter intake in wild herbivores. Nature 197:307-308

Verme LJ (1969) Reproductive patterns of white-tailed deer in relation to nutritional plane. J Wild Manage 33:881-884

Wang LCH (1979) Time patterns and metabolic rates of natural torpor in the Richardson's ground squirrel. Can J Zool 57:149 155

Werner EE, Hall DJ (1974) Optimal foraging and the size selection of prey by the bluegill sunfish (Lepomis macrochinus). Ecology $55: 1042-1052$

Westoby M (1974) An analysis of diet selection by large generalist herbivores. Am Nat 108:289-304

Zegers DA, Williams OW (1977) Seasonal cycles of body weight and lipids in Richardson's ground squirrel, Spermophilus richardsonii elegans. Acta Theriol 22:380-383

Received December 1, 1988/Received in revised form Apri1 5, 1989/ Accepted April 25, 1989 